3 Guillete, R., Berling, C. M., and Finkelstein, J. D., Clinical Proceedings of the Children's Hospital of the District of Columbia, 1971, 27, 224.

4 Huttenlocher, P. R., Fournal of Pediatrics, 1972, 80, 845.

5 Olson, L. C., et al., Pediatrics, 1971, 47, 707.

- Bourgeois, C., et al., American fournal of Clinical Pathology, 1971, 56, 558.

$?$ Reynolds D. W., et al., Fournal of Pediatrics, 1971, 80, 429.

8 Partin, J. C., Schubert, W. K., and Partin, J. S., New England fournal of Medicine, 1971, 285, 1339.

Glasgow, A. M., Cotton, R. B., and Dhiensiri, K., American fournal of

Diseases of Children, 1972, 124, 827.
10 Olson, L. C., et al., American fournal of Diseases of Children, 1970, 120, 1.

11 Bourgeois, C. H., et al., Laboratory Investigation, 1971, 24, 206.

Glasgow, A. M., Cotton, R. B., Bourgeois, C. H., and Dhiensiri, K. American fournal of Diseases of Children, 1972, 124, 834.

13 Trauner, D. A., David, R. B., Madge, G., Brown, R. E., and Mamumes, P., Pediatric Research, 1972, 6, 329.

14 Walker, C. O., McCandless, D. W., McGarry, J. D., and Schenker, S., Fournal of Laboratory and Clinical Medicine, 1970, 76, 569.

15 Zieve, L., Zieve, F. J., Doizaki, W. M., and Glisdorf, R. B., Abstracts of the 5th Meeting of the International Association for the Study of the Liver, p. 41, 1971

Williams, R., British Medical Bulletin, 1972, 28, 114

Schwartz, A. D., fournal of Pediatrics, 1971, 78, 326

18 Brown, R. E., and Madge, C. E., Pediatrics, 1971, 48, 162.

\section{Calcaneal Fractures}

Fractures of the os calcis are important because of the severe disability they cause. They occur mainly in men whose work requires them to climb heights or who are heavy manual workers. They incapacitate patients frequently at the peak of their earning power and at a time when their financial commitments are greatest.

The fractures were classified by $R$. Watson-Jones into three types. ${ }^{1}$ This classification is useful because it reflects the degree of trauma causing the injury and it indicates the prognosis. Type A fractures are isolated fractures of the calcaneum, and they may be comminuted. They are caused by less severe trauma than the others, and the resultant prognosis is good. Type B fractures have minimal injury to the posterior talo-calcaneal joint, and type $\mathrm{C}$ show significant displacement and involvement of this joint. The last two types of fracture are rarely shown in full by the standard radiographs of the bone, and special views of the posterior talo-calcaneal joint are essential.

S. Nade and P. R. W. Monahan have reported a series of 203 fractures of the calcaneum in 185 patients seen at the Radcliffe Infirmary, Oxford. ${ }^{2}$ Almost a quarter were occupied in climbing heights and another quarter were heavy manual workers. Children were rarely affected. Falls from heights were responsible for most of the type $C$ fractures, whereas less severe accidents, such as twisting, falls from kerbs or stairs, or crush injuries, were responsible mainly for type A and $B$ fractures. Type $C$ was the most common fracture and type B was the least common. In this series $28 \%$ of the patients had other injuries. These were mainly to the same foot or limb, but five patients had vertebral fractures and 13 had other lesions.

Pain, bruising, and swelling of the heel are the presenting features of this fracture, and the heels are tender to touch on examination. In the face of such an obvious injury further examination of the patient might be thought unnecessary, but this is essential because of the risk of other injuries, especially vertebral fractures. The pain from these calcaneal fractures is so severe that it may mask the pain from the other injuries. A full radiographic investigation of all tender areas is essential.

The treatment reported by Nade and Monahan in their study was not uniform, and this variation reflects the general opinion among surgeons. While all their patients were treated conservatively, they recommend that the place of sur- gery should be reviewed. Most surgeons treat their patients conservatively, but the exact method of treatment varies. Crepe and wool bandages and raising the affected foot with the patient rested in bed comprise the simplest treatment. Admission to hospital is indicated if there are other severe injuries. Analgesics initially are essential and trypsin-chymotrypsin tablets may help to disperse the haematoma. The application of a well-padded plaster below the knee often provides the patient with more comfort. Because the os calcis in type $C$ fractures is broadened when viewed from behind, manipulation under anaesthetic during application of the plaster is sometimes undertaken in an attempt to mould the bone into a more normal shape. This enables the patient to wear a normal shoe later when he has recovered. Surgical treatment is essential in all open fractures, but in closed fractures opinions vary about surgery. Operative procedures include raising the superior border of the os calcis with a Steinmann pin inserted through the heel and bone-grafting the os calcis to achieve the same result and finally fusion. Early fusion was advocated by Watson-Jones because he was so disappointed by the long-term results of these fractures, but most people wait to see the end product before embarking on this procedure. The fusion undertaken might be a local subtalar fusion or even a triple fusion involving the subtalar and midtarsal joints.

Nade and Monahan's patients who were admitted to hospital stayed for an average duration of 6.7 days and were away from work for 15.6 weeks, the range for the latter being $7 \cdot 3$ weeks for type A and 23 weeks for type C. Symptoms can be expected to improve for two years, but even after this time patients may have complaints. These are pain, local swelling, stiffness, cold feet, and cramps. Patients with type C have the worst symptoms. In Nade and Monahan's study $57 \%$ of patients were so affected, and many suffered loss of agility, being unable to stand unaided on tiptoes, walk on uneven ground, and climb ladders; $17 \%$ had been granted a governmental disability pension ranging from 5 to $20 \%$. Of the patients with bilateral fractures, only one from whom the information was available returned to work within six months.

Patients suffering these fractures are faced with a long period of pain and disability, loss of pay, loss of function, and perhaps loss of work. A satisfactory treatment has yet to be devised.

\footnotetext{
1 Watson-Jones, R., Fractures and foint Injuries, 4th ed., vol. 2., p. 866 Edinburgh, Livingstone, 1955.

2 Nade, S., and Monahan, P. R. W., Injury, 1973, 4, 201.
}

\section{Glucagon and Diabetes}

Diabetes mellitus is characterized by relative or absolute deficiency of insulin. Three of its main biochemical featureshyperglycaemia, increased mobilization of body fat, and increased protein catabolism-appear to be primarily caused by lack of the normal restraining influence of insulin on gluconeogenesis, triglyceride hydrolysis, and protein turnover respectively. Insulin's action in regulating fat mobilization and protein turnover appears to be mainly at the level of the peripheral tissues. By favouring protein synthesis and inhibiting proteolysis, insulin controls the flow of glucogenic amino-acids to the liver, where they may be subsequently converted to glucose. ${ }^{1}$ In a similar manner insulin promotes 
triglyceride synthesis and inhibits lipolysis in adipose tissue and restricts the flow of free fatty acids to the liver, where they may be oxidized and converted to ketone bodies. In addition to its peripheral action insulin also has a central effect in regulating gluconeogenesis, suppressing the activity of several hepatic enzymes. ${ }^{2}$ In states of insulin deficiency, such as fasting and diabetes mellitus, these enzymes are activated.

It would seem from this that most if not all of the biochemical features of diabetes can be accounted for simply by a deficiency of insulin. What, if any, is the role of glucagon in the regulation of these pathways? This is a question that has been asked repeatedly, but it is only recently that sufficient data have been available to begin to piece together this jig-saw puzzle and make a coherent picture.

In addition to the polypeptide hormone glucagon produced by the alpha cells of the islets of Langerhans, there is in the circulation at least one structurally and immunologically similar hormone arising from the mucosa of the small intestine, enteroglucagon, whose biological role remains even less clear than that of pancreatic glucagon itself.

Pancreatic glucagon (henceforth referred to as glucagon) has biological actions that, at least in man, tend to oppose those of insulin. Undoubtedly the most potent of these is one leading to the breakdown of hepatic glycogen to glucose. This action is brought about by the stimulation of hepatic adenyl cyclase, leading to the formation of $3^{\prime}-5^{\prime}$ cyclic AMP, which subsequently activates the enzyme phosphorylase and inhibits glycogen synthetase. A sudden rise of glucagon in the portal veins results in the immediate mobilization of hepatic stores of glycogen and a rapid rise of blood glucose.

The elegant studies of S. R. Bloom and colleagues ${ }^{3}$ have shown that in a variety of stressful conditions the secretion of glucagon may be stimulated by the sympathetic nervous system. This response and the subsequent hyperglycaemia are probably an integral part of the "flight or fight" mechanism. Under these conditions this secretion of insulin is inhibited by the sympathetic activity and glycogen stores are rapidly depleted. In this role glucagon acts along with the catecholamines in the metabolic responses to threatening situations and is clearly acting as a "stress hormone". What is the relationship between this and diabetes?

A recent paper by W. A. Müller and colleagues 5 has confirmed the previous observations of R. Assan and colleagues ${ }^{6}$ that patients in diabetic coma frequently have very high concentrations of glucagon in the plasma. They studied a group of 26 patients admitted with acutely uncontrolled diabetes mellitus, many of whom had ketoacidosis. The initial concentration of plasma glucagon was raised in most of the patients and it subsequently fell to normal levels with successful treatment of their hyperglycaemia. Though the initial plasma glucagon was strikingly raised in only a few of the diabetic patients, there were interesting direct correlations between the plasma concentrations of glucagon and some of the clinical indices of the severity of the ketoacidosis-namely, initial blood glucose concentration, respiratory rate, and the number of hours of treatment required until plasma acetone was negative at a $1: 2$ dilution in two minutes on crushed Acetest tablets. The authors conclude that the raised glucagon levels may "adversely influence the disease." By this they mean that the presence of increased secretion of glucagon might exaggerate certain of the metabolic consequences of insulin deficiency. It is likely that glycogenolysis and gluconeogenesis will be stimulated but the evidence that these modest rises of plasma glucagon will stimulate lipolysis and aggravate ketoacidosis is less good. Though a lipolytic action of glucagon can be demonstrated in vitro, the concentrations of glucagon required are much greater than those present in vivo, and the careful studies of A. Cherrington and his co-workers ${ }^{7}$ have clearly shown that concentrations of glucagon that lead to hyperglycaemia in the dog do not affect plasma concentrations of free fatty acids.

What then is the meaning of the findings of Müller and colleagues? The evidence suggests that the raised levels of glucagon reported in diabetic ketoacidosis may reflect a humoral response either to some predisposing cause of the condition or to the metabolic stress itself. Additional studies from R. H. Unger's laboratory ${ }^{8}$ clarify the situation further. These workers found raised concentrations of plasma glucagon in a group of non-diabetic patients with acute bacterial infections. Plasma glucagon averaged $409 \mathrm{pg} / \mathrm{ml}$ in a group of six patients with severe infections, strikingly similar to the mean of $390 \mathrm{pg} / \mathrm{ml}$ reported for the group with diabetic ketoacidosis and approximately five times higher than fasting values in healthy persons. Infection is known to be one of the commonest predisposing factors to the development of ketoacidosis in otherwise well controlled diabetics, and it seems reasonable to conclude that in the presence of a fixed input of insulin (such as occurs in most ketosis-prone diabetics) stress-induced hyperglucagonaemia will contribute to a deterioration in the diabetic control. Irrespective of whether or not the glucagon responses are primary or secondary, the message is clear. The development of an infection in an insulin-treated diabetic patient is an indication for increasing the dose of insulin (or for providing temporary insulin treatment for patients just maintained in balance on diet with or without oral agents). In this way lifethreatening ketoacidosis should be avoidable in many patients.

1 Felig, P., Metabolism, 1973, 22, 179

${ }^{2}$ Weber, G., Singhal, R. L., and Srivastava, S. K., Advances in Enzyme Regulation, 1965, 3, 43.

${ }^{3}$ Bloom, S. R., Daniel, P. M., Johnston, D. I., Ogawa, O., and Pratt, O. E., Quarterly fournal of Experimental Physiologv, 1973, 58, 99.

5 Müller, W. A., Faloona, G. R., and Unger, R. H., American fournal of Medicine, 1973, 54, 52.

- Assan, R., Hautecouverture, G., Guillemant, S., Dauchy, F., Protin, P., and Derot, M., Pathologie|Biologie, 1969, 17, 1095.

7 Cherrington, A., Vranic, M., Fono, P., and Kovacevic, N., Canadian fournal of Phvsiology and Pharmacology, 1972, 50, 946.

8 Rocha, D. M., Santeusanio, F., Faloona, G. R., and Unger, R. H., New England . Fournal of Medicine, 1973, 288, 700.

\section{Ascorbic Acid and Common Colds}

Many people believe that fresh fruit and vegetables or vitamin C are good for colds, while others believe in garlic or alcohol, but the use of ascorbic acid in large doses has been andently promoted by Professor Linus Pauling, 1 twice a Nobel prize winner (chemistry 1954, peace 1962). He argues that primitive man and his anthropoid ape relatives, such as the gorilla, which eats barrow loads of leaves, consume far more ascorbic acid than we do, and that, though the minimum daily requirements, perhaps $50 \mathrm{mg}$ a day, are sufficient to prevent gross disease such as scurvy, higher daily intakes will increase health further. He has pointed things to say too about the high cost of small amounts of ascorbic acid sold over the counter. Many people are taking substantial 